\title{
OBSERVATIONS ON THE GROWTH AND MATURATION OF INDIAN BOYS IN DURBAN, SOUTH AFRICA
}

\author{
BY \\ J. H. ABRAMSON \\ From the Department of Social, Preventive, and Family Medicine, University of Natal, and the Institute of
Family and Community Health, Durban, South Africa
}

Groups of children vary considerably in their growth and maturation. Such differences have been ascribed to nutritional, ethnic, climatic, and other factors.

This study was carried out on Indian pupils at a day school in an extremely poor "slum" neighbourhood of Durban, the social conditions of which have been described by Kark and Chesler (1956) and Abramson (1959). The majority of the boys came from Hindustani or Tamil speaking Hindu homes; most were the descendants of 19th century settlers in South Africa (Palmer, 1957).

There was a high prevalence of signs of malnutrition among the boys examined. Most boys had some degree of skin xerosis, and many showed evidence of phrynoderma, "permanent goose flesh" (Platt, 1945), glossitis, a "buccal frieze" (Corkill, 1934), lesions at the angles of the lips, a fatigue posture, or other abnormalities commonly associated with malnutrition. In 1954 a survey revealed a very high prevalence of worm infestation among the children at this school-roundworm in 83 per cent., whipworm in 86 per cent., and hookworm in 32 per cent.

The ages of the children examined ranged from 7 to 17 years. The number of boys enrolled at the school, however, showed a sharp drop from the age of 15 , the numbers aged $12,13,14,15$, and 16 years respectively being $40,42,41,26$, and 12 . Among Indian girls in Durban, an association .has been shown between commencing adolescence and school-leaving (Kark, 1953), and it was regarded as possible (though for other reasons) that the maturer boys might also be more likely to leave school than less mature boys of the same age. Accordingly, it was possible that from the age of 15 the sample was biased; the main analyses were therefore confined to boys aged 7 to 14 years.

\section{METHODS}

The boys were examined in May-June, 1952 (in the middle of the school year), in November, 1952 (towards the end of the same school year), and in May, 1953. Most boys were examined at least twice. They were weighed and measured on an Avery personal scale with a graduated metal upright and a wooden headpiece. They were clothed only in short trousers. The sexual maturity of the boys was assessed in accordance with the simple clinical criteria suggested by Ellis (1946, 1947), which take into account both genital and hair development.

The boys were classified into three categories:

(a) Non-pubescent.--Infantile or minimal genital development and no pigmented pubic hair.

(b) Pubescent.-Early genital developmentgrowth in length of the penis or a recognizable increase in the size of the testes; or coarse pigmented pubic or axillary hair.

(c) Adolescent.-Advanced genital development (increase in girth of the penis and testes at least half the adult size); pubic hair.

In almost all cases, the boys' ages were based on official birth records. The age used was that at the child's last birthday.

A cross-sectional analysis was undertaken of the weights, heights, and maturity grades of the boys aged 7 to 14 (599 observations). In addition, a 
longitudinal study was made of the weight and height increments of the 199 boys who were measured twice in the 1952 school year. The interval between the two examinations ranged from $23 \frac{1}{2}$ to $25 \frac{1}{2}$ weeks.

\section{RESULTS}

Weight and Height.- The findings are shown in Table 1 and Figs 1 and 2 (opposite).

For comparison, Fig. I. includes growth curves of London boys (Daley, 1950) and of Indian boys resident in Nairobi (Adalja, Gautama, and Sethi, 1949) and in South India (Rao, Taskar, and Ramanathan, 1954).

Fig. 2 shows the mean heights and weights of the boys in relation to their sexual maturity.

Growth Vclocity.--The mean increments during a period of $23 \frac{1}{2}$ to $25 \frac{1}{2}$ weeks, between May-June and
TABLE II

WEIGHT AND HEIGHT INCREMENTS ATTAINED IN $5 \stackrel{4}{4}$ MONTHS BY INDIAN BOYS IN DURBAN

\begin{tabular}{|c|c|c|c|c|c|}
\hline \multirow{3}{*}{$\begin{array}{c}\text { Initial } \\
\text { Age } \\
\text { (yrs) }\end{array}$} & \multirow{3}{*}{$\begin{array}{c}\text { No. of } \\
\text { Subjects }\end{array}$} & \multicolumn{4}{|c|}{ Increment } \\
\hline & & \multicolumn{2}{|c|}{ Weight (lb.) } & \multicolumn{2}{|c|}{ Height (in.) } \\
\hline & & Mean & S.D. & Mean & S.D. \\
\hline $\begin{array}{l}7^{*} \\
8^{*}\end{array}$ & $\begin{array}{l}13 \\
18\end{array}$ & $\begin{array}{l}3 \cdot 25 \\
1 \cdot 99\end{array}$ & - & $\begin{array}{l}1 \cdot 23 \\
0.92\end{array}$ & - \\
\hline 9 & 36 & $2 \cdot 46$ & $1 \cdot 33$ & 0.92 & $0 \cdot 38$ \\
\hline 10 & 25 & $2 \cdot 54$ & $1 \cdot 09$ & $0 \cdot 88$ & $0 \cdot 39$ \\
\hline 11 & 26 & $3 \cdot 39$ & $1 \cdot 98$ & 0.90 & 0.61 \\
\hline 12 & 23 & $4 \cdot 24$ & $2 \cdot 27$ & $1 \cdot 07$ & $0 \cdot 39$ \\
\hline 13 & 27 & $5 \cdot 35$ & $2 \cdot 97$ & $1 \cdot 04$ & 0.47 \\
\hline 14 & 31 & $6 \cdot 81$ & $2 \cdot 68$ & $1 \cdot 25$ & 0.40 \\
\hline
\end{tabular}

* The mean increments for boys aged 7 and 8 years (combined) were $2 \cdot 52 \mathrm{lb}$. (S.D. $1 \cdot 50$ ) and 1.05 in. (S.D. $0 \cdot 42$ ).

TABLE: I

MEAN WEIGHTS AND HEIGHTS OF INDIAN BOYS IN DURBAN

\begin{tabular}{|c|c|c|c|c|c|c|c|c|c|c|c|c|c|}
\hline \multirow{3}{*}{$\begin{array}{c}\text { Measure- } \\
\text { ment }\end{array}$} & \multirow{3}{*}{ Age (yrs) } & \multicolumn{9}{|c|}{ Maturity Grade } & \multirow{2}{*}{\multicolumn{3}{|c|}{ Total Group }} \\
\hline & & \multicolumn{3}{|c|}{ Non-pubescent } & \multicolumn{3}{|c|}{ Pubescent } & \multicolumn{3}{|c|}{ Adolescent } & & & \\
\hline & & No. & Mean & S.D. & No. & Mean & S.n. & No. & Mean & S.D. & No. & Mean & S.D. \\
\hline \multirow{10}{*}{ Weight (lb.) } & $7-$ & 43 & $42 \cdot 92$ & $4 \cdot 88$ & & & & & & & 43 & $42 \cdot 92$ & $4 \cdot 88$ \\
\hline & $8-$ & 53 & $47 \cdot 45$ & $5 \cdot 78$ & & & & & & & 53 & $47 \cdot 45$ & $5 \cdot 78$ \\
\hline & 9- & 93 & $50 \cdot 71$ & $5 \cdot 90$ & & & & & & & 93 & $50 \cdot 71$ & $5 \cdot 90$ \\
\hline & 10 & 107 & $53 \cdot 83$ & $6 \cdot 10$ & & & & & & & 107 & $53 \cdot 83$ & $6 \cdot 10$ \\
\hline & $11-$ & 66 & $59 \cdot 00$ & $6 \cdot 39$ & 6 & $70 \cdot 20$ & $\ldots$ & & & & 72 & $59 \cdot 93$ & $7 \cdot 59$ \\
\hline & 12 & 53 & $61 \cdot 73$ & $8 \cdot 35$ & 23 & $72 \cdot 49$ & $10 \cdot 79$ & 2 & $96 \cdot 54$ & - & 78 & $65 \cdot 80$ & $11 \cdot 34$ \\
\hline & $13-$ & 28 & $65 \cdot 38$ & $7 \cdot 97$ & 36 & $74 \cdot 14$ & $10 \cdot 15$ & 11 & $88 \cdot 11$ & - & 75 & $72 \cdot 91$ & $11 \cdot 59$ \\
\hline & 14 & 9 & $65 \cdot 19$ & - & 54 & $75 \cdot 13$ & $9 \cdot 26$ & 15 & $96 \cdot 14$ & - & 78 & 78.03 & $13 \cdot 42$ \\
\hline & $15-$ & 4 & $61 \cdot 64$ & - & 31 & $85 \cdot 51$ & $12 \cdot 22$ & 13 & $102 \cdot 63$ & - & & & \\
\hline & $16-$ & 1 & $55 \cdot 10$ & $\cdots$ & 16 & $91 \cdot 10$ &.- & 12 & $104 \cdot 94$ & $\ldots$ & & & \\
\hline \multirow{10}{*}{ Height (in.) } & $7-$ & 43 & $46 \cdot 45$ & $2 \cdot 06$ & & & & & & & 43 & $46 \cdot 45$ & $2 \cdot 06$ \\
\hline & $8-$ & 53 & $48 \cdot 23$ & $2 \cdot 28$ & & & & & & & 53 & $48 \cdot 23$ & $2 \cdot 28$ \\
\hline & 9 & 93 & $49 \cdot 80$ & $1 \cdot 95$ & & & & & & & 93 & $49 \cdot 80$ & 1.95 \\
\hline & $10-$ & 107 & $50 \cdot 90$ & $2 \cdot 31$ & & & & & & & 107 & $50 \cdot 90$ & $2 \cdot 31$ \\
\hline & $11-$ & 66 & $53 \cdot 27$ & $2 \cdot 11$ & 6 & $55 \cdot 87$ & - & & & & 72 & $53 \cdot 47$ & $2 \cdot 30$ \\
\hline & 12 & 53 & $54 \cdot 29$ & 3.02 & 23 & $56 \cdot 61$ & 1.95 & 2 & $62 \cdot 01$ & - & 78 & $55 \cdot 22$ & $3 \cdot 08$ \\
\hline & $13-$ & 28 & $55 \cdot 24$ & $2 \cdot 34$ & 36 & $57 \cdot 98$ & $2 \cdot 30$ & 11 & $61 \cdot 57$ & - & 75 & $57 \cdot 48$ & $3 \cdot 11$ \\
\hline & 14 & 9 & $56 \cdot 16$ & - & 54 & $58 \cdot 98$ & $2 \cdot 10$ & 15 & $62 \cdot 67$ & $\cdots$ & 78 & $59 \cdot 38$ & $2 \cdot 84$ \\
\hline & $15-$ & 4 & $55 \cdot 65$ & - & 31 & $60 \cdot 99$ & $2 \cdot 80$ & 13 & $64 \cdot 27$ & - & & & \\
\hline & $16-$ & 1 & $52 \cdot 20$ & - & 16 & $62 \cdot 05$ & - & 12 & $65 \cdot 09$ & - & & & \\
\hline
\end{tabular}

Notes: The standard deviation was not calculated for groups containing less than twenty observations.

For reasons stated in the text, the mean values for the total group were not calculated bevond the age of 14 years. 


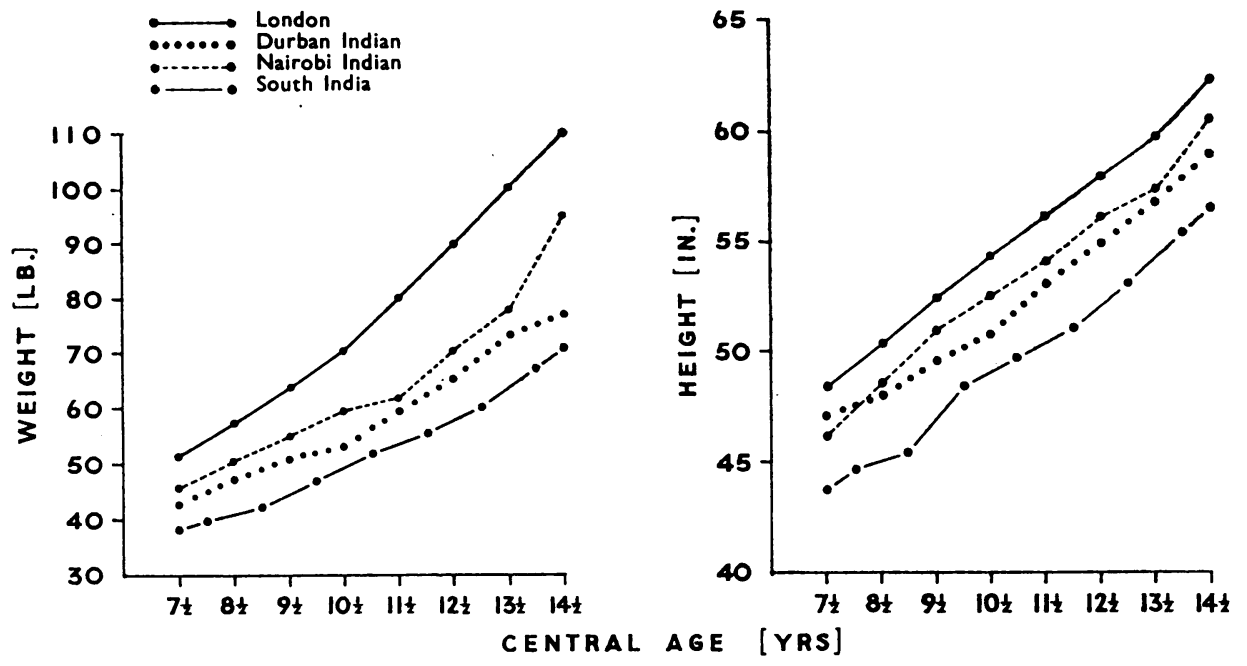

FIG. 1.-Mean weights and heights of Indian boys in Durban and of London boys and Indian boys elsewhere.
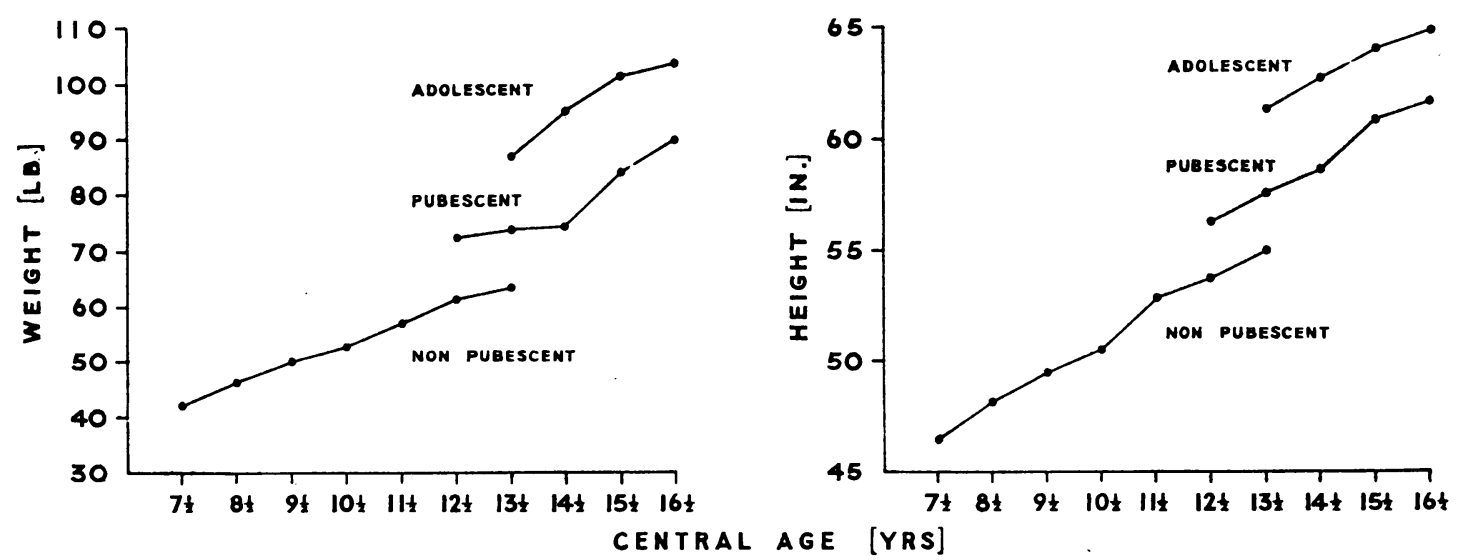

FIG. 2.-Mean weights and heights of Indian boys in Durban, by maturity grade.

November, 1957, are shown in Table II and Fig. 3 (overleaf).

Sexual Maturity.-The findings are shown in Table III and Fig. 4 (overleaf), together with comparable data for English, Nigerian, and Scottish boys (Ellis, 1948, 1950; Provis and Ellis, 1955).

\section{Discussion}

The boys' measurements fall considerably short of English norms. In view of their poor nutritional state, it is likely that this is largely a reflection of nutritional influences, and that the role played by ethnic, climatic, and other factors is a secondary one.
This probability is supported by comparison with the weights and heights of Indian children elsewhere. The measurements of these boys tend to be lower than those of well-nourished or privileged Indian boys, and similar to or higher than those of malnourished Indian boys. The Durban boys' weights and heights are, for example, somewhat lower than those of Indian boys in Nairobi in 1948 (Fig. 1). These Nairobi boys appear to have been in a relatively good nutritional condition. Adalja and others (1949) state that:

"With the exception of xerosis in one student and dry and rough skin in another we did not come across any manifestation of deficiency disease. Angular stomatitis, keratomalacia, Bitot's spots, etc., were 

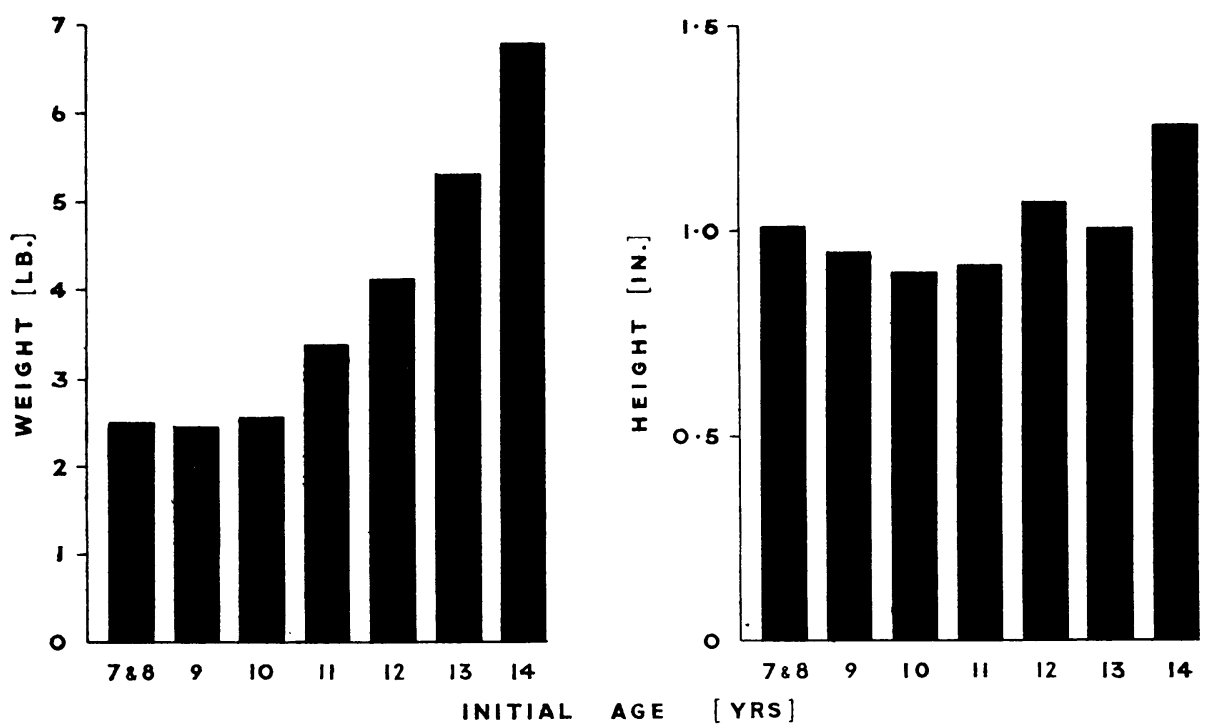

FIG. 3.- Mean weight and height increments attained by Indian boys in Durban during $5 \frac{1}{2}$ months.

not encountered. . . 7.6 per cent. of children were classified from the point of view of nutrition [using a rough clinical assessment] as subnormal. We met very few cases with poor nutrition".

On the other hand, the Durban boys' weights correspond closely with those found in Nairobi boys 17 years previously (Hargreaves, 1931). The Durban heights are somewhat higher, at all ages, than those reported for the Nairobi boys in 1931.

The measurements of boys from poor and lowermiddle class families in South India, such as those described by Rao and others (1954), tend to be considerably lower than those of the Durban children (Fig. 1). While it is difficult to be sure that these boys are more malnourished than the Durban boys, it is clear that their nutritional state is poor. Skin dryness, dullness, and roughness are reported in 70 per cent. of children in this region of India (Patwardhan, 1954), and the prevalence of other individual signs of malnutrition ranges from 0.5 to 15.5 per cent. (Rao and others, 1954). The weights and heights of the Durban boys appear to be superior to those of most samples of native Indian boys studied (Patwardhan, 1952), except possibly for those living in the Punjab, Bengal, and Bihar.

A comparison with published figures for Bombay schoolboys (Mehta, Mhaskar, and Vaidyanathan, 1941) yields a two-way contrast. Hindu boys from well-off homes are heavier and taller than the boys in Durban, while those from a lower economic stratum are considerably lighter and shorter.
Similarly, "upper class" boys in Ceylon (Nicholls, 1951) are taller and heavier than the boys in Durban. while poorer class boys in Ceylon are shorter and lighter.

As there may be considerable ethnic and other non-nutritional differences between these various groups of Indian and Cingalese boys, such comparisons cannot prove that the weight and height differences are produced mainly by nutritional factors. They are however, in general, consistent with this thesis.

There is a well-documented relationship between growth and sexual maturation. Not only is there a well-defined growth spurt around the age of puberty, but early-maturing children tend to be larger, from early in childhood, than later-maturing children of the same age. Further, it has been shown that the greater weight of children in higher social groups can be accounted for on the assumption that they mature earlier (Hammond, 1953).

The present study provides evidence of a delay in maturation compared with that seen in groups of better-nourished non-Indian children. Unfortunately no comparable longitudinal studies of Indian children could be found.

It appears that the puberty growth-spurt starts later and reaches its peak later among these Durban boys than among British boys. There is little evidence of accelerated weight-growth before the age of 11 , or of accelerated height-growth before the age of 12 (Fig. 3). The figures given by Hammond (1957) 
TABLE III

SEXUAL MATURITY OF INDIAN BOYS IN DURBAN, COMPARED WITH ENGLISH*, NIGERIANt, AND SCOTTISH $\ddagger$ BOYS

\begin{tabular}{|c|c|c|c|c|c|c|c|c|c|c|c|c|}
\hline \multirow{3}{*}{ Age (yrs) } & \multicolumn{12}{|c|}{ Percentage of boys at each Maturity Grade } \\
\hline & \multicolumn{4}{|c|}{ Non-pubescent } & \multicolumn{4}{|c|}{ Pubescent } & \multicolumn{4}{|c|}{ Adolescent } \\
\hline & Durban & English & Nigerian & Scottish & Durban & English & Nigerian & Scottish & Durban & English & Nigerian & Scottish \\
\hline 9 & 100 & 100 & 100 & 100 & - & - & - & - & - & $\cdots$ & - & - \\
\hline 10 & 100 & $95 \cdot 0$ & $93 \cdot 5$ & 100 & $\cdots$ & $5 \cdot 0$ & $6 \cdot 5$ & - & - & -- & - & - \\
\hline 11 & $91 \cdot 7$ & $86 \cdot 5$ & $78 \cdot 8$ & $95 \cdot 0$ & $8 \cdot 3$ & $13 \cdot 5$ & $21 \cdot 2$ & $5 \cdot 0$ & - & - & - & - \\
\hline 12 & $67 \cdot 9$ & $64 \cdot 2$ & $57 \cdot 9$ & $77 \cdot 5$ & $29 \cdot 5$ & $35 \cdot 8$ & $40 \cdot 8$ & $22 \cdot 5$ & $2 \cdot 6$ & - & $1 \cdot 3$ & - \\
\hline 13 & $37 \cdot 3$ & $47 \cdot 4$ & $44 \cdot 4$ & $47 \cdot 1$ & $48 \cdot 0$ & $43 \cdot 7$ & $38 \cdot 9$ & $49 \cdot 4$ & $14 \cdot 7$ & $8 \cdot 9$ & $16 \cdot 6$ & $3 \cdot 5$ \\
\hline 14 & $11 \cdot 5$ & $12 \cdot 5$ & $17 \cdot 1$ & $21 \cdot 4$ & $69 \cdot 2$ & $39 \cdot 2$ & $48 \cdot 5$ & $60 \cdot 7$ & $19 \cdot 2$ & $48 \cdot 3$ & $34 \cdot 3$ & $17 \cdot 9$ \\
\hline
\end{tabular}
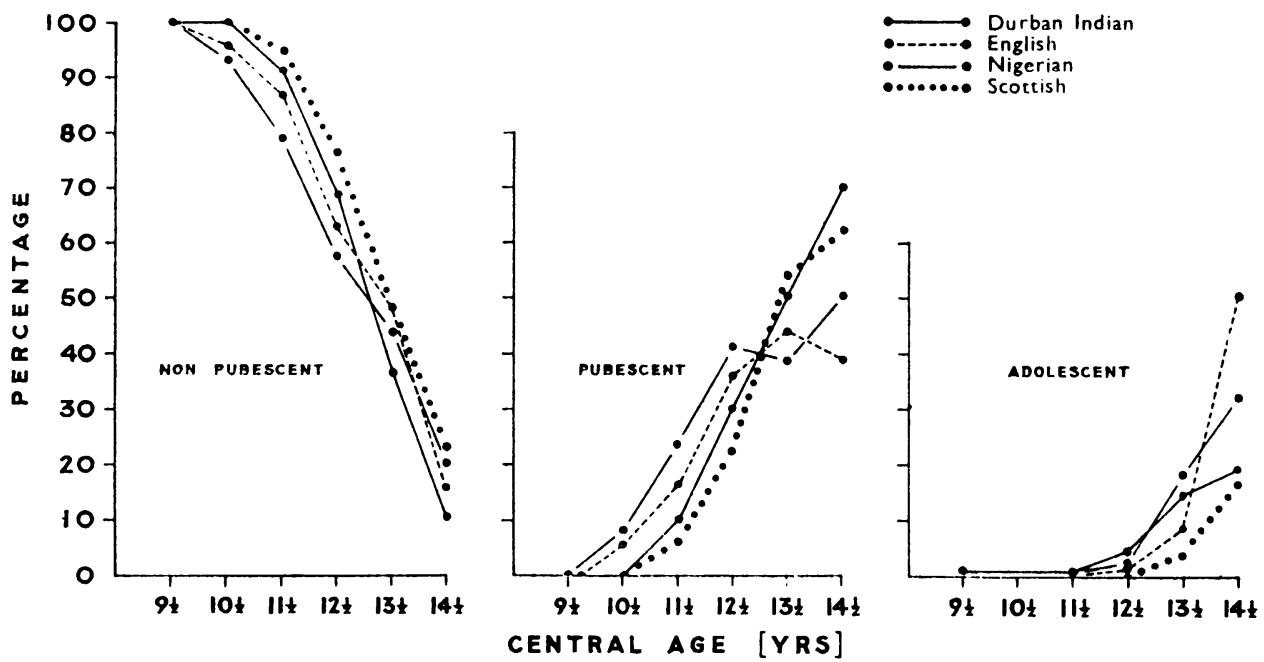

FIci. 4.-Sexual maturity of Indian boys in Durban, compared with English, Nigerian, and Scottish boys.

for British boys, however, indicate that the weightgrowth of 10-year-olds is significantly greater than that of 9-year-olds $(P<0.02)$, and that the heightgrowth of 11 -year-olds is significantly greater than that of 10-year-olds $(P<0.02)$. The velocity of British boys' height-growth has passed its peak by the age of 14, the height-growth of 14-year-olds being lower than that of 12- or 13-year-olds; the difference from the 12-year-olds is significant $(P<0.02)$, while that from the 13-year-olds falls just short of significance. The height-growth of the 14-year-old Durban boys, on the other hand, is greater than that of either 12- or 13-year-olds; the difference from 12- and 13-year-olds combined is statistically significant $(P<0 \cdot 05)$. It appears from the cross-sectional data provided by Rao and others (1954) for boys in South India that the maximal growth-spurt of these children also occurs after their 14th birthday.

There is a possible fallacy in these comparisons. The British figures represent growth during a period of 12 months, while the Durban figures relate to growth during a period of $5 !$ months. Thus the British figure for boys whose initial age is 14 is based on boys whose final age is in some cases just below 16, whereas the corresponding Durban figure relates to boys whose final age is, at the most, just below $15 !$. However, though this comparative "lag" in the British figures may partly account for the differences noted, it seems unlikely that it can completely explain them.

Comparison with studies of White boys in the United States provides some support for the view that the growth-spurt of the Indian children is 
delayed. In particular, it appears that the rate of height-growth in American boys tends to reach its peak earlier than in the Durban boys. Stolz and Stolz (1951), for example, found that the velocity of height-growth reached its peak at the mean age of 13.99 years. Other studies (Gray and Ayres, 1931; Simmons, 1944; Stuart and Meredith, 1946) similarly indicate that the average rate of height-growth after the 14th birthday is not greater (as in the Durban boys) but less than or similar to that which occurs immediately before the 14th birthday. This is not, however, an invariable finding (Bayley, 1956). Furthermore, it is difficult to demonstrate that the onset of the puberty growth-spurt occurs earlier in American boys than in these Durban boys. In view of this conflicting evidence, the possibility cannot be completely excluded that the delay in the Durban boys' growth-spurt is more apparent than real.

The findings in respect of sexual maturity similarly provide some indication, but no conclusive proof, of a delayed onset of puberty and a delayed adolescence. Comparable data, using the same grading method, are available for English (Ellis, 1948), Nigerian (Ellis, 1950), and Scottish boys (Provis and Ellis, 1955).

In comparison with English boys, the proportion who are non-pubescent is higher among the Durban boys until the age of 12 , and the proportion who are pubescent is correspondingly lower. At age 10 this difference is statistically significant $(P<0.05)$. Later, at age 14, the proportion of boys who are adolescent is significantly lower among the Durban boys $(P<0.001)$ and the proportion still pubescent is correspondingly higher.

Beyond the age of 14, this difference is particularly striking. At the ages of 15 and 16, 27 and 41 per cent. respectively of the Durban boys are adolescent. The corresponding figures for English boys are 69 and 76 per cent. This difference may, however, be partly due to a tendency for more mature Durban boys of 15 and 16 to leave school, and hence to leave the sample.

There are similar discrepancies from the Nigerian findings, though only at age 10 is statistical significance reached $(P<0.01)$.

Consideration must be given to the possibility that these differences are not real but reflect variations in the application of the grading criteria. While the method of maturity grading used is of great value in clinical practice, it is to some extent, as Ellis (1950) has said, arbitrary, and leaves room for variation between observers in the grading of border-line cases. Thus to some extent it may give different results in different hands. However, if such variations have been of a random kind, they are likely to have had little effect on the overall trend of the findings. A consistent bias, on the other hand, would be likely to have produced differences involving all ages, e.g. a consistently higher proportion of non-pubescent boys. It thus seems likely that, although there may have been variations in the technique of assessment, there is in fact a real difference between the maturation of these boys and that of the English and Nigerian boys.

If this is so, it may well be largely due to malnutrition. As Tanner (1955) has stated: "so far as can be ascertained from present data, neither climate nor race influence the time of adolescence as greatly as nutrition, at least where the differences in nutritional status are wide". Though there is as yet little direct evidence of the effect of nutrition on the sexual development of boys, there is much indirect evidence.

The nutritional state of the Durban boys studied was apparently poor by comparison both with the English boys studied, who were having a "liberal diet" (Ellis, 1946), and with the Nigerian boys. Ellis (1950) states that: "in general, the physique and nutrition of the [Nigerian] children appeared reasonably good", though in one group of boys (comprising 12 per cent. of the total sample), there was evidence of widespread vitamin B deficiency. The boys were relatively privileged children. Ellis does not describe their physical growth, but children of the same ethnic groups (Ibo and Yoruba) living elsewhere in Nigeria, are considerably taller and heavier than the Durban boys (Nicol, 1956).

A recent study of Edinburgh boys, on the other hand, indicates that these children, who are presumably much better nourished than the Durban children, mature later. As Fig. 4 indicates, fewer Edinburgh boys than Durban boys are more mature at ages 11 to 14 . Though this difference is significant only at age $13(P<0.02)$, the trend is a consistent one.

This finding must be either the effect of a bias in the application of the grading techniques, or the outcome of factors other than nutritional. Provis and Ellis (1955) make no comment on the possible reasons for the apparent discrepancy between the rate of maturation of Scottish and English children.

Apart from this single discordant finding, the results that have been described are in general not inconsistent with the thesis that the malnutrition of the Indian boys manifests itself in poor growth and delayed maturation. It may be noted that it has been found among Indian girls in Durban that the less privileged children have a significantly later menarche than those from better-off families (Kark, 1956). The age at menarche of Indian girls in 
Durban as a whole tends to be later than that of middle and upper class groups in the United States, similar to that of underprivileged American groups, and earlier that that of four out of six groups of native Indian and Cingalese girls (Kark, 1953).

The association found in these boys between malnutrition, poor growth, and indications of delayed maturation is consistent with a largely nutritional explanation for these latter phenomena. However, in view of the reservations which have been discussed, this conclusion should be treated with caution. A full evaluation of the significance of the findings must wait on similar studies of Indian boys elsewhere, or of better-nourished Indian boys in Durban itself.

\section{SUMMARY}

Observations were made of the weight, height, and sexual maturity of a group of malnourished Indian schoolboys in Durban, South Africa. The sexual maturity of the boys was graded in accordance with the criteria suggested by Ellis. Comparisons were made with data for Indian and other boys elsewhere.

The boys were found to be shorter and lighter than English boys. Their weights and heights tended to be lower than those of privileged or better-nourished Indian boys elsewhere, and similar to or higher than those of malnourished Indian boys elsewhere.

There was evidence suggesting that the puberty growth-spurt began later than among British boys, and that it reached its peak later than among British boys and possibly later than among boys in the United States.

Puberty occurred later than among English and privileged Nigerian boys, but sexual maturation appeared to occur earlier than among Edinburgh boys.

Apart from this last finding, the results indicate an association in Indian boys in Durban between malnutrition, poor growth, and delayed maturation, and are in general consistent with a largely nutritional explanation for these latter phenomena.

I am indebted to Professor S. L. Kark and Dr. E. Kark for their interest and criticism, to Medical Aide E. C. Jali for his assistance with the measurements, to Mrs. K. M. Wolfson for the charts, and to the school authorities and the boys for their cooperation.

\section{REFERENCES}

Abramson, J. H. (1959). "The Lakeside Health Service". Awaiting publication.

Adalja, K. V., Gautama, M. D., and Sethi, S. (1949). E. Afr. med. J., 26, 109.

Bayley, N. (1956). J. Pediat., 48, 187.

Corkill, N. L. (1934). Lancet, 1, 1387.

Daley, A. (1950). "Report on the Heights and Weights of School Pupils in the County of London in 1949". London County Council, London.

Ellis, R. W. B. (1946). Arch. Dis. Childh., 21, 181.

Ellis, R. W. B. (1946). Arch. Dis. Ch.

(1948). Arch. Dis. Childh., 23, 17

- (1950). Brit. med. J., 1, 85 .

Gray, H., and Ayres, J., G. (1931). "Growth in Private School Children". Univ. of Chicago Press, Chicago. (Quoted by Krogman, 1950).

Hammond, W. H. (1953). Brit. J. prev. soc. Med., 7, 231.

- (1957). Ibid., 11, 131 .

Hargreaves, G. M. (1931). Kenya and E. Afr. med. J., 8, 124.

Kark, E. (1953). S. Afr. J. clin. Sci., 4, 23.

- (1956). S. Afr. J. Lab. clin. Med., $2,84$.

Kark, S. L., and Chesler, J. (1956). Ibid, 2, 134.

Krogman, W. M. (1950). "Handbook of the Measurement and Interpretation of Height and Weight in the Growing Child", No. 48. Monogr. Soc. Res. Child Dev., 13, No. 3.

Mehta, J. N., Mhaskar, K. W.' S., and Vaidyanathan, L. S. (1941). $J$. Indian med. Ass., 10, 143.

Nicholls, L. (1951)" "Tropical Nutrition and Dietetics", 3rd ed. Baillière, Tindall and Cox, London.

Nichol, B. M. (1956). Brit. J. Nutr., 10, 181.

Palmer, M. (1957). "The History of the Indians in Natal" (Natal Regional Survey Series, Vol. 10). Oxford University Press, Cape Town.

Patwardhan, V. N. (1952). "Nutrition in India". Indian J. med. Sci., Bombay.

(1954). Calcutta med. J., 51, 117.

Platt, B. S. (1945). Brit. med. Bull., 3, 179.

Provis, H. S., and Ellis, R. W. B.'(1955). Arch. Dis. Childh., 30, 328.

Rao, K. Someswara, Taskar, A. D., and Ramanathan, M. K. (1954). Indian J. med. Res., 42, 55.

Simmons, K. (1944). "Brush Foundation Study of Child Growth and Development. II. Physical Growth and Development". No. 37. Monog. Soc. Res. Child. Dev., 9, No. 1 .

Stolz, H. R., and Stolz, L. M. (195i). "Somatic Development of Adolescent Boys". MacMillan, New York.

Stuart, H. C., and Meredith, H. V. (1946). Amer. J. publ. Hlth, 36, 1365.

Tanner, J. M. (1955). "Growth at Adolescence". Blackwell Scientific Publications, Oxford. 